\title{
Isolated DC-DC UPS based in a Forward- Forward Converter Analysis and Design
}

\author{
L.A. Flores, O. Garcia, Member IEEE, A. Roman and M.S. Esparza, Member IEEE
}

\begin{abstract}
This paper presents the analysis, design and simulation from a simple DC-UPS converter with integrated back-up and automatic transition. This converter makes automatic transition between the main $\mathrm{AC}$ and the battery when a failure occurs, and it delivers uninterrupted DC power to the load through two independent power sources of commercial input power and battery power. The converter has the following characteristics: automatic transition between the main and the battery, no additional control to detect failure in the main, single structure, galvanic isolation, multi output voltages capability and only one switch control for two operation modes normal and back-up. The analysis, design, simulation and experimental results for this converter are presented.
\end{abstract}

Index Terms - Automatic transition, battery charger, DC-DC converter.

\section{NOMENCLATURE}

Main $\mathrm{AC}=$ rms voltage from ac line, $\mathrm{V}_{\mathrm{in}}=\mathrm{dc}$ voltage entrance from rectifiers, $\mathrm{V}_{\mathrm{BAT}}=$ battery voltage, $\mathrm{V}_{\mathrm{o}}=$ output dc voltage, $d=$ duty cycle, $\mathrm{P}_{\mathrm{o}}=$ output power, $\mathrm{L}_{\mathrm{M}}=$ magnetizing inductance, $\mathrm{I}_{\mathrm{LM}}=$ magnetizing current.

\section{INTRODUCTION}

$\mathrm{T}$ HE use of DC-UPS has been increased in the last decades in the equipment of telecommunications and the portable electronic equipment [1]-[9]. This cause that every time improvements in their operation as in their structure for reduce size, weight, cost and dynamic response are made. Although several approaches for to solve above problems are made [2][12], only a few of them take into account the Automatic Transition in their structure [10]-[13]. Traditional solution to design a DC-UPS is using two stages: the first include a battery charger and the second uses a dc-dc converter to regulate the output voltage (Figure 1). This structure provides a low efficiency since the total energy is processed twice before it is delivered to the load and in addition uses two control loops, one to regulate the battery voltage and the other to regulate the output voltage. This paper presents a DC-UPS based in a forward-forward converter in order to solve some of the problems that were mentioned before and including automatic transition between the main ac and the battery.

This work was supported by the Mexican Government through Project PROMEP-103.5/07/2562 and Universidad Autonoma de Aguascalientes through project PII08-2N.

L.A. Flores and A. Roman are with the Universidad Autónoma de Aguascalientes, Departamento de Sistemas Electrónicos, Av. Universidad \#940, 20100 Aguascalientes, Ags. MEX. (e-mail: lflores@correo.uaa.mx).

O. García is with the Universidad Politécnica de Madrid, Madrid 28040, Spain (e-mail: o.garcia@upm.es).

M.S. Esparza is with the Instituto Tecnólogico de Aguascalientes Departamento de Ingeniería Eléctrica, Ags. MEX. (e-mail: msespa@ieee.org).

978-1-4244-1766-7/08/\$25.00 (C) 2008 IEEE

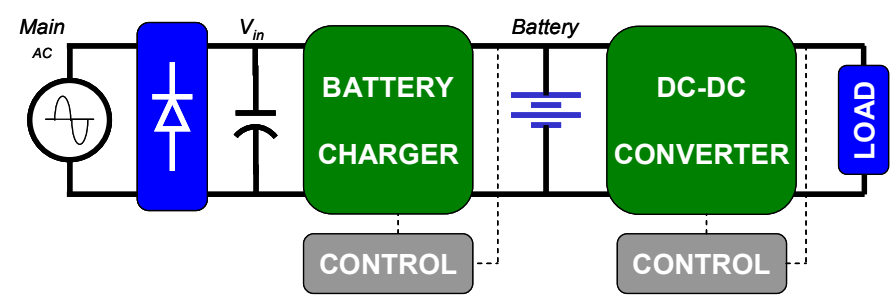

Figure 1. Traditional DC-UPS including rectifier, battery charger, battery, DC-DC converter, and two control loops.

\section{PROPOSED CONVERTER}

The general structure of the proposed DC-UPS converter is known as CIBAT (Converters with Integrated Back-up and Automatic Transition) and it is presented in [13]. CIBAT is a family of four converters where each one consist of a transformer, main output, battery charger, two diodes $\left(D_{N}\right.$ and $D_{B}$ ) that make the automatic transition and two entrances, the input dc voltage from rectifiers $V_{\text {in }}$ and the battery. Both entrances are connected in the primary winding of the transformer but the battery makes it through a centered tap with $\mathrm{D}_{\mathrm{B}}$. Therefore both entrances share the same transformer, switch, and control loop obtaining in a simple circuit with only one stage (Figure 2).

CIBAT can adopt different topologies; it depends in how is transferred the energy to the load and how is charged the battery. The principal structure from CIBAT uses only one converter with two outputs forward or flyback one of them to feed the load and the other to charge the battery. Consequently four combinations can be made to build CIBAT, ForwardForward, Forward-Flyback, Flyback-Forward and FlybackFlyback where the first name corresponds with the converter made between the dc voltage entrance $\left(V_{\text {in }}\right)$ and the load, the second name correspond with the converter made between the dc voltage entrance $\left(V_{\text {in }}\right)$ and the battery $\left(V_{\mathrm{BAT}}\right)$. The four combinations are shown in Figure 3.

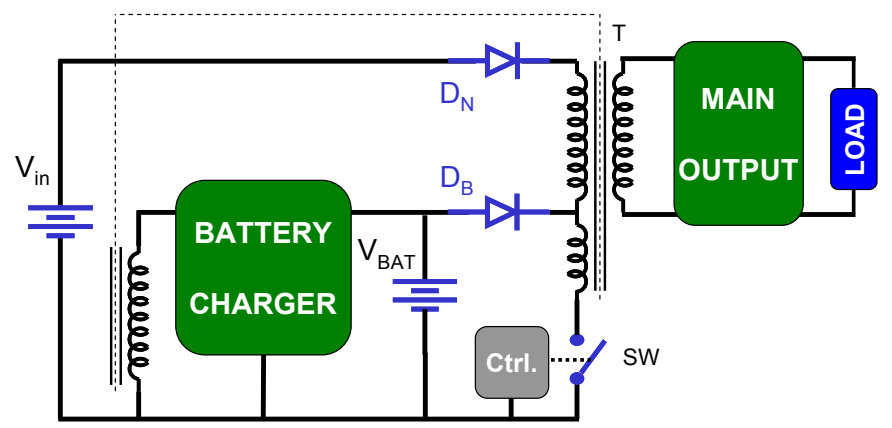

Figure 2. General structure of Converters with Integrated Back-up and Automatic Transition 

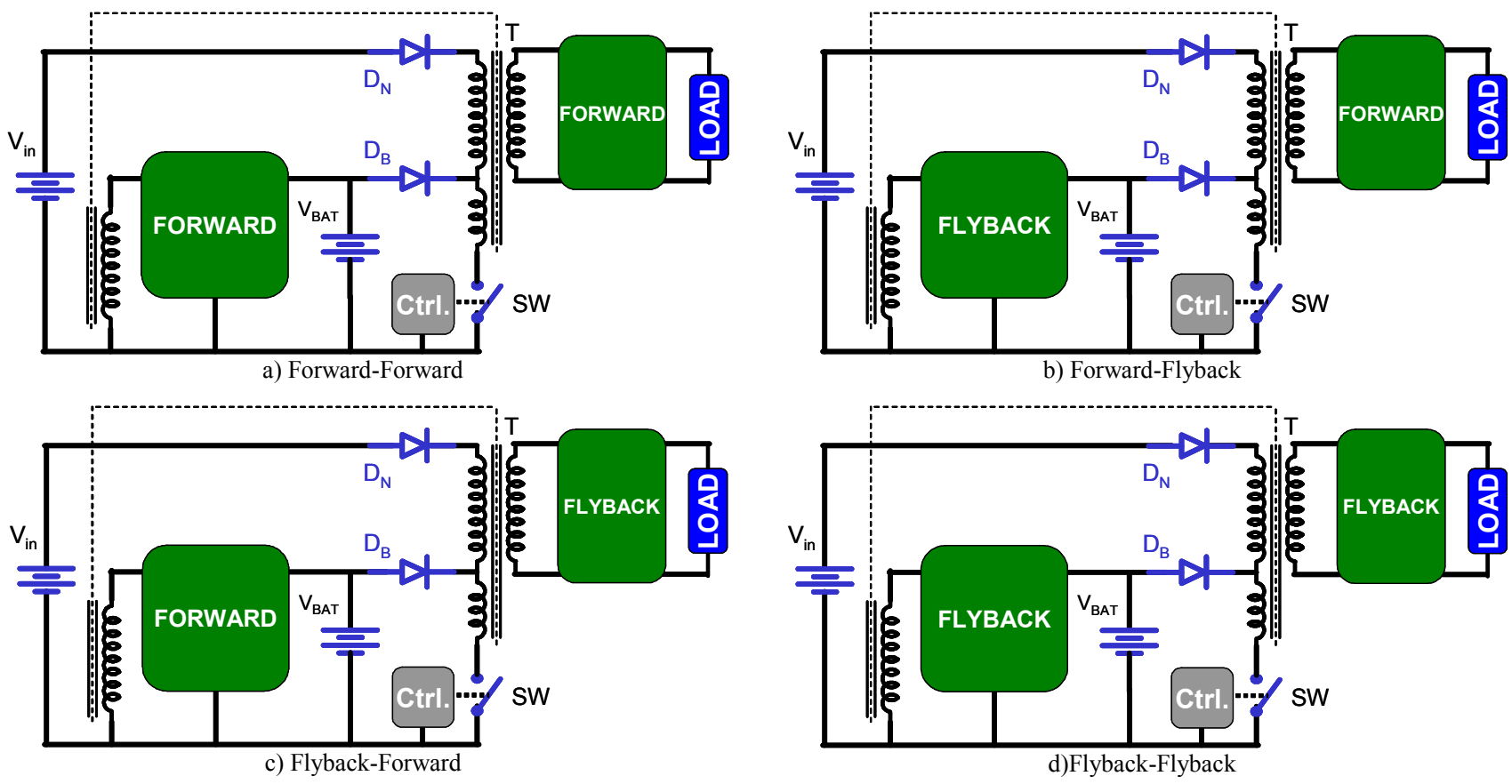

Figure 3. Four combinations to construct CIBAT

\section{A. CIBAT characteristics}

Single structure: These arrays allow to design a DC-UPS with only one stage achieving high efficiency, small size and low cost.

Operation modes: These topologies have only two operation modes, normal plus battery charger and back-up mode. Both operation modes are in CCM and share same switch, control loop, and transformer.

Multi-output voltages: Additional windings can be placed in the transformer in order to obtain multi- outputs voltages (Figure 4); this is another characteristic that can be taken advantage of in the design of the converter.

One switch: This is another important advantage of this kind of converters because all of them use only one switch, sharing the primary winding of the transformer, and uses only one control loop compensation for both operation modes. This makes the design of converter very simple and is other important characteristic to be considered in industrial applications.

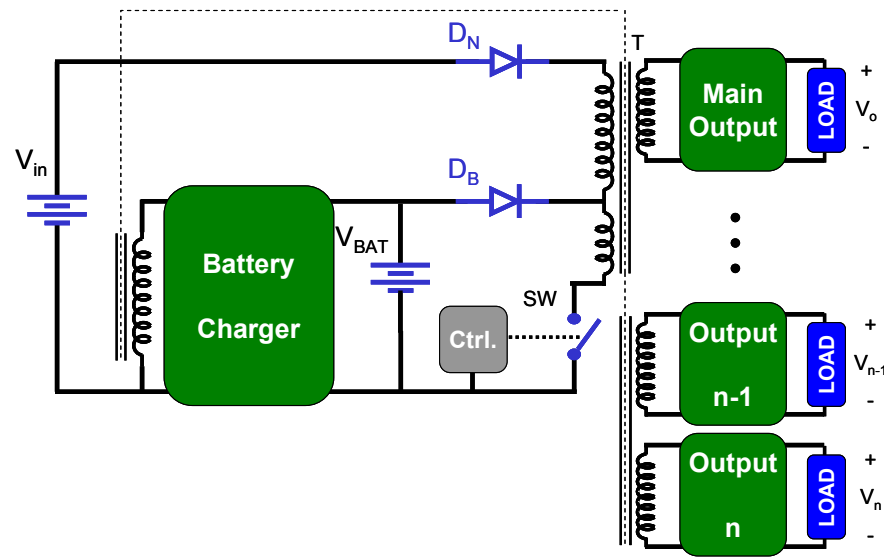

Figure 4 Additional windings to obtain multi-output voltages.
Automatic Transition: This is possible under the idea to use two diodes to make this transition $\left(D_{N}\right.$ and $\left.D_{B}\right)$, when the converter is fed by the dc voltage entrance $\left(\mathrm{V}_{\mathrm{in}}\right), \mathrm{D}_{\mathrm{N}}$ conduce and automatically $\mathrm{D}_{\mathrm{B}}$ is blocked. When suddenly a problem occurs in the dc voltage entrance, automatically $D_{B}$ conduces allowing that the system be fed immediately from the battery. Since both entrances share the same transformer with a centered tap connection through $\mathrm{D}_{\mathrm{B}}$ the output voltage does not suffer any change in its value. This idea is important because it is not necessary to use any auxiliary circuit control to detect when a fail occurs, allowing fast dynamic response.

\section{B. Circuit operation}

CIBAT topologies have only two operation modes Normal plus battery charger and Back-up operation mode. Both operation modes are in CCM and share same switch, control loop, and transformer.

Normal plus battery charger operation mode. The principle of operation in normal plus battery charger mode in these converters is to transfer energy from $V_{\text {in }}$ to the load and charge the battery simultaneously. In this operation mode $\mathrm{D}_{\mathrm{N}}$ is turned on and $D_{B}$ is turned off (Figure 5). In this operation mode $D_{B}$ is never in a conduction state guaranteeing thus the correct operation of the converter.

Back-up operation mode. When a failure occurs suddenly in $\mathrm{V}_{\mathrm{AC}}, \mathrm{V}_{\text {in }}$ decrease and $\mathrm{D}_{\mathrm{B}}$ makes an automatic transition to back-up mode due to the fact that the voltage in the anode is higher than in the cathode voltage in $\mathrm{D}_{\mathrm{B}}$, allowing feeding in the load through the battery using the same switch and transformer (Figure 6). When AC main returns, $V_{\text {in }}$ increases and $D_{B}$ is blocked since the cathode voltage is higher than the battery voltage $\left(\mathrm{V}_{\mathrm{BAT}}\right)$, reaching normal operation mode again. 


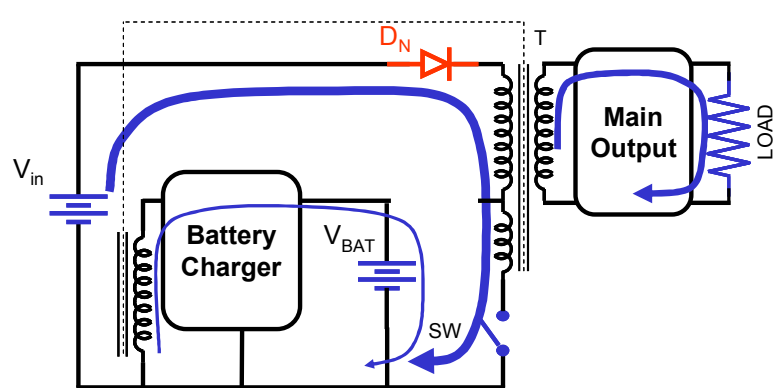

Figure 5. Normal operation mode.

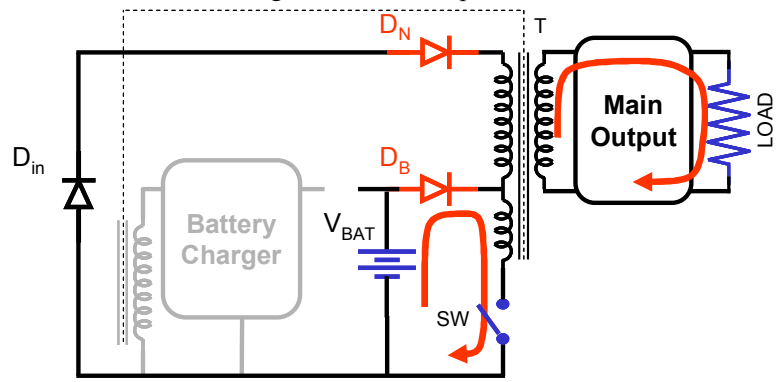

Figure 6. Back-up operation mode.

\section{FORWARD-FORWARD DC-UPS}

As initial analysis from CIBAT family, Forward-Forward topology was selected to be designed, simulated and constructed. Figure 7 shows the structure of Forward-Forward DC-UPS, this topology needs an auxiliary system in order to eliminate the magnetizing current $\left(i_{\text {mag }}\right)$. This system is formed by a RCD network $\left(\mathrm{D}_{5}, \mathrm{C}_{\mathrm{c}}\right.$, and $\left.\mathrm{R}_{\mathrm{c}}\right)$ put in parallel with the switch [14] that operates like a discontinuous conduction mode boost converter. The main output is integrated by $\mathrm{D}_{1}$, $\mathrm{D}_{2}, L_{1}$ and $\mathrm{C}_{\mathrm{o}}$; battery charger is formed by $\mathrm{D}_{3}, \mathrm{D}_{4}, L_{2}$ and $\mathrm{C}_{\mathrm{BAT}}$. Both outputs share the same transformer TR, switch $\mathrm{M}$ and control. The converter is fed by $\mathrm{V}_{\mathrm{BAT}}$ and $\mathrm{V}_{\text {in }}$ that is obtained from the $\mathrm{AC}$ rectifier input and capacitive $\mathrm{C}_{\mathrm{in}}$ filter. In order to ensure a good operation of the converter, the $\mathrm{RCD}$ network has to eliminate the magnetizing current in both operation modes (Normal plus battery charger and Back-up). Both operation modes are presented.

The two principal operation modes can be identifier in this converter as in any from the CIBAT family, normal plus battery charger mode, and back-up mode.
Equivalent circuit for this operation mode is shown in Figure 8 , where $D_{B}$ is blocked, $V_{A C}$ is considered like a simple DC input voltage $\left(\mathrm{V}_{\text {in }}\right)$ and $\mathrm{Na}$ consider the total primary winding. Design this topology resulted very simple, due to is exactly as a simple forward converter with two outputs that share the primary winding of the transformer. Applying balance volts-seconds in $L_{l}$ with continuous conduction mode (CCM) the equation that defines the gain of the converter based on duty cycle $d_{N}$ and turns ration in the transformer TR is:

$$
\mathrm{V}_{\mathrm{o}}=d_{N} \mathrm{~V}_{\mathrm{in}} \frac{\mathrm{N}_{\mathrm{c}}}{\mathrm{N}_{\mathrm{a}}}, \quad 0 \leq d_{N} \leq\left(1-d_{1}\right)
$$

Where $d_{N}=$ duty cycle in normal operation mode, $d_{l}=$ time to eliminate magnetizing current, $V_{\text {in }}=d c$ voltage entrance from rectifiers, $\mathrm{N}_{\mathrm{a}}=$ total primary winding turns and $\mathrm{N}_{\mathrm{c}}=$ output winding turns. In the same form, applying voltsbalance in $L_{2}$ with continuous conduction mode (CCM) in order to obtain the equation that defines the voltage $\mathrm{V}_{\mathrm{BAT}}$ in battery charger is:

$$
\mathrm{V}_{\mathrm{BAT}}=d_{N} \mathrm{~V}_{\text {in }} \frac{\mathrm{N}_{\mathrm{d}}}{\mathrm{N}_{\mathrm{a}}}, \quad 0 \leq d \leq\left(1-d_{1}\right)
$$

Average output current in normal mode is:

$$
\hat{i}_{o \mathrm{~N}}=\frac{\mathrm{P}_{\mathrm{o}}}{\mathrm{V}_{\mathrm{o}}}
$$

To calculate the inductance value as function from a ripple current in $L_{l}\left(\Delta i_{N}\right)$ and frequency is:

$$
L_{1}=\frac{\mathrm{V}_{\mathrm{o}}-\mathrm{V}_{\mathrm{o}}{ }^{2} \frac{\mathrm{Na}}{\mathrm{Nc}}}{\Delta i_{\mathrm{N}} \cdot f}
$$

the peak current in the inductor $L_{1}$ is:

$$
i_{\mathrm{pkN}}=\hat{i}_{o \mathrm{~N}}+\frac{\Delta i_{N}}{2}
$$

\section{A. Normal plus battery charger operation mode}

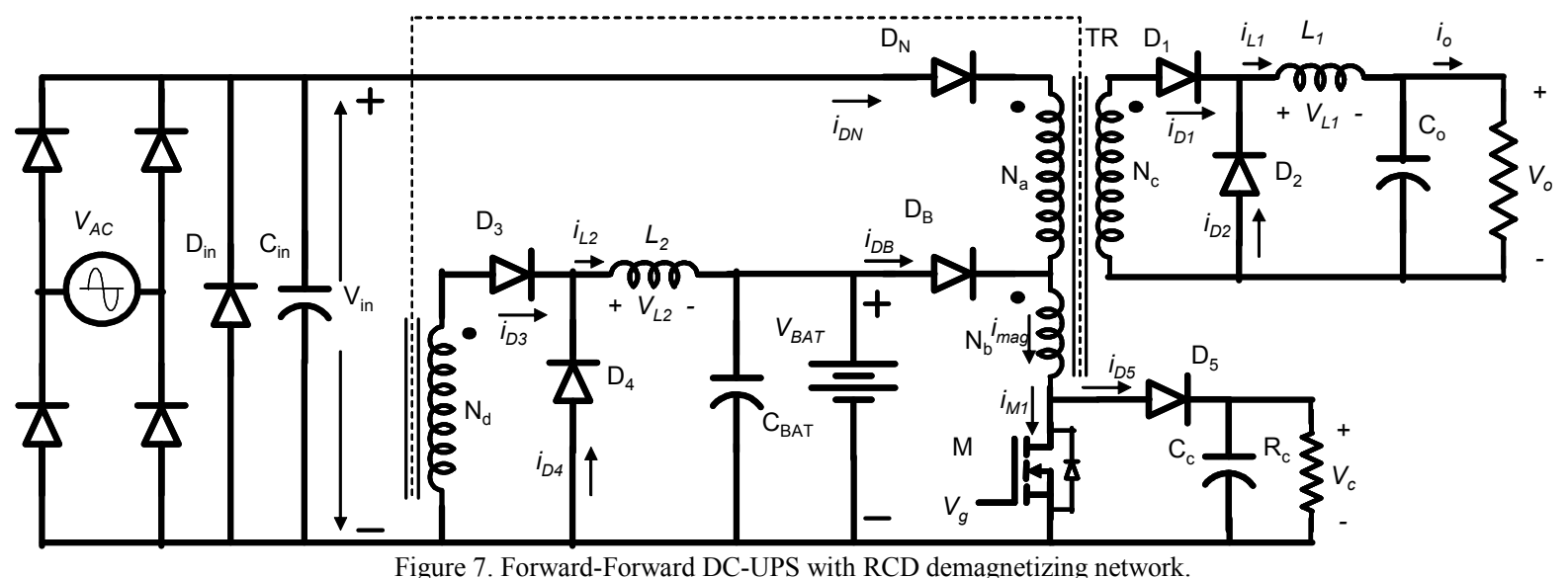




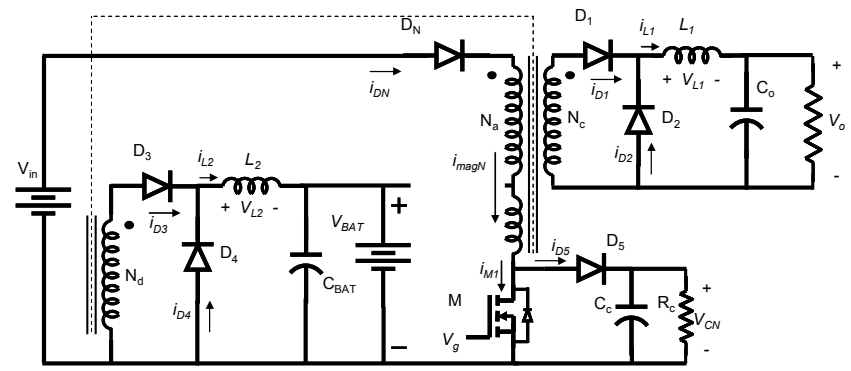

Figure 8. Normal plus battery charger mode

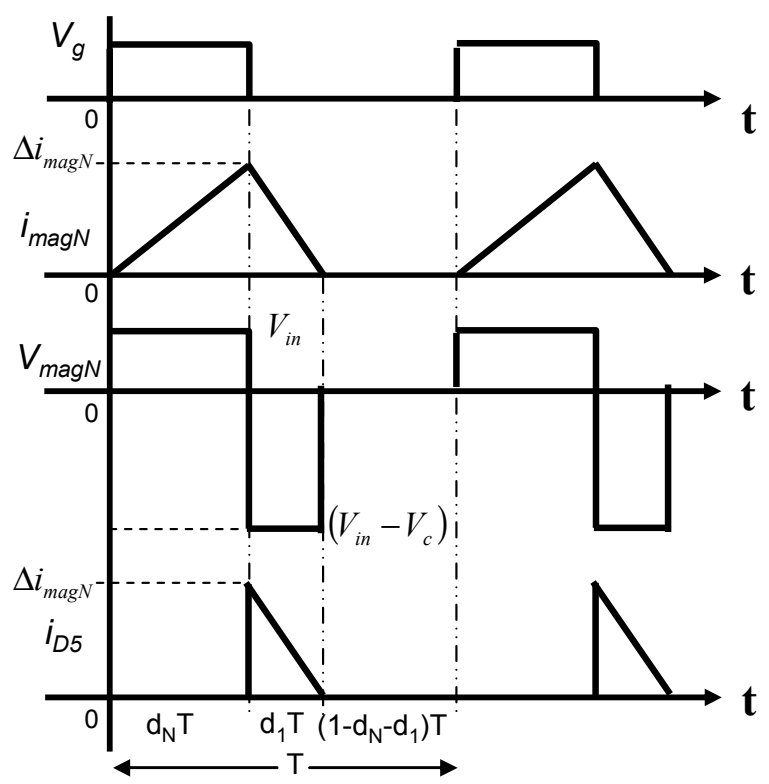

Figure 9. Magnetizing current in normal operation mode

Magnetizing inductance in transformer (TR) varies in each operation mode too, in the case of normal plus battery charger; it will be determined by equation (6)

$$
L_{\text {magN }}=\mathrm{A}_{\mathrm{L}} \mathrm{N}_{\mathrm{a}}{ }^{2}
$$

Where, $A_{L}$ is the inductance factor from the core; the output voltage in RCD network $\left(\mathrm{V}_{\mathrm{c}}\right)$ is like a discontinuous conduction mode (DCM) boost converter and is calculated with equation (7)

$$
\mathrm{V}_{\mathrm{CN}}=\frac{\mathrm{V}_{\text {in }}}{2}\left(1+\sqrt{1+\frac{2 d_{N}{ }^{2} R_{c} T}{L_{\text {mag } N}}}\right)
$$

Peak magnetizing current $\left(\Delta_{\text {imagN }}\right)$ and the time to eliminate it $\left(d_{1}\right)$ every switching period can be obtained form Figure 9 with equations (8) and (9) respectively.

$$
\begin{gathered}
\Delta i_{\text {magN }}=\frac{V_{\text {in }} d_{N} T}{L_{\text {magN }}} \\
d_{1}=\frac{\mathrm{V}_{\mathrm{CN}}}{\mathrm{V}_{\text {in }}} \frac{2 L_{\text {magN }}}{R_{C} d_{N} T}
\end{gathered}
$$

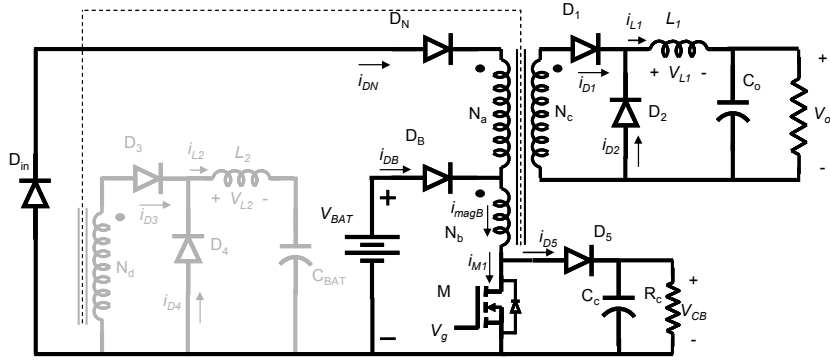

Figure 10. back-up operation mode

\section{B. Back-up operation mode}

When a failure occurs suddenly in $\mathrm{V}_{\mathrm{AC}}, \mathrm{V}_{\text {in }}$ decrease and $\mathrm{D}_{\mathrm{B}}$ make automatic transition to back-up mode due to the voltage in anode is higher than cathode voltage in $\mathrm{D}_{\mathrm{B}}$ allowing fed the load through the battery using the same switch and transformer (Figure 9).

In this operation mode the battery charger has to be disconnected from the battery in order to avoid that the energy return to the battery through the transformer causing an efficiency reduction. The battery disconnection from the charger can be made with a simple low frequency interrupter or a simple relay. In addition $V_{\text {in }}$ is substituted by a diode $\left(D_{\text {in }}\right)$ that is formed by full diode rectifier or it can be placed as an additional ultra fast rectifier in parallel with $\mathrm{C}_{\text {in }}$ in order to help to manage the magnetizing current $\left(\mathrm{i}_{\mathrm{magB}}\right)$ that results from this operation mode too. When $A C$ main comeback $V_{\text {in }}$ increase and $\mathrm{D}_{\mathrm{B}}$ is blocked since the cathode voltage is higher than battery voltage $\left(\mathrm{V}_{\mathrm{BAT}}\right)$, achieving normal operation mode again. Equation (10) calculated the output voltage in this operation mode

$$
\mathrm{V}_{\mathrm{o}}=d_{B} \mathrm{~V}_{\mathrm{BAT}} \frac{\mathrm{N}_{\mathrm{c}}}{\mathrm{N}_{\mathrm{b}}}, \quad 0 \leq d_{B} \leq\left(1-d_{2}\right)
$$

Where $d_{B}=$ duty cycle in Back-up mode, $d_{2}=$ time to eliminate magnetizing current, $\mathrm{V}_{\mathrm{BAT}}=\mathrm{dc}$ voltage entrance battery, $\mathrm{N}_{\mathrm{b}}=$ proportional primary winding turns and $\mathrm{N}_{\mathrm{c}}=$ output winding turns. Equation (11) determines the magnetizing inductance in transformer (TR) in this operation mode.

$$
L_{m a g B}=\mathrm{A}_{\mathrm{L}} \mathrm{N}_{\mathrm{b}}{ }^{2}
$$

Equation (12) determines the output voltage $\left(\mathrm{V}_{\mathrm{CB}}\right)$.

$$
\mathrm{V}_{\mathrm{CB}}=\frac{\mathrm{V}_{\mathrm{BAT}}}{2}\left(1+\sqrt{1+\frac{2 d_{B}{ }^{2} R_{c} T}{L_{\text {magN }}}}\right)
$$

Peak magnetizing current $\left(\boldsymbol{\bullet}_{\text {imag }}\right)$ and the time to eliminate it $\left(\mathrm{d}_{2}\right)$ are respectively.

$$
\begin{gathered}
\Delta i_{\text {mag } B}=\frac{V_{i n} d_{B} T}{L_{m a g B}} \\
d_{2}=\frac{\mathrm{V}_{\mathrm{CB}}}{\mathrm{V}_{\text {in }}} \frac{2 L_{m a g N}}{R_{C} d_{B} T}
\end{gathered}
$$




\section{Design considerations}

Design has to take into account the total relation among all the components and semiconductors in the converter as input voltage variation, output power and the possible relation turns in the transformer. Analysis and design of this converter only have to take into account restrictions in construction of the converter because it uses two topologies very known, sharing same transformer, switch and control. The desirable duty cycles in each operation mode, determine the possible turn ration in the transformer.

One important consideration to guarantee the correct operation of the converter in normal operation mode, is to ensure that cathode voltage in $D_{B}$ has to be higher for any rectifier input voltage $\left(\mathrm{V}_{\text {in }}\right)$. In order to accomplish this, equation (15) has to be satisfied.

$$
\mathrm{V}_{\text {in }} \frac{\mathrm{N}_{\mathrm{b}}}{\mathrm{N}_{\mathrm{a}}}>\mathrm{V}_{\text {BAT }}
$$

\section{SIMULATION RESULTS}

In order to verify the operation principle from the converter, a prototype circuit was simulated in PSPICE with the characteristics named in TABLE I. Schematic circuit for simulation is in Figure 11; this circuit simulates the transition from Normal operation mode to Back-up mode and vice versa back-up to normal mode. Simulation was made in open loop changing the respective duties cycles for each operation mode by a logic circuit, no control loop was simulated. Both entrances were $V_{\text {in }}$ and $V_{\text {BAT. }}$. Results of the converter with suddenly fails in main appear and it is possible to observe that the output voltage does not show significant change in its value. It is observed that the output voltage does not show any transitory when a fail occurs and it made automatic transition from one operation mode to another. Figures 12 and 13 shown waveforms from the converter when a fails occurs and when voltage entrance returns. Dynamic response of the system can be improved adjusting the control loop with the use of the transfer function of the converter.

\begin{tabular}{|l|c|}
\hline Topology & $\begin{array}{c}\text { Forward-Forward with } \\
\text { RCD }\end{array}$ \\
\hline Main AC & $127 \mathrm{~V}_{\text {rms }}$ \\
\hline $\begin{array}{l}\text { DC voltage entrance } \\
\text { from rectifiers }\left(\mathrm{V}_{\text {in }}\right)\end{array}$ & $180 \mathrm{~V}$ \\
\hline Output voltage $\left(\mathrm{V}_{\mathrm{o}}\right)$ & $48 \mathrm{~V}$ \\
\hline Battery voltage $\left(\mathrm{V}_{\mathrm{BAT}}\right)$ & $24 \mathrm{~V}$ \\
\hline Output power $\left(P_{o}\right)$ & $100 \mathrm{~W}$ \\
\hline Switching frequency $\left(f_{s}\right)$ & $100 \mathrm{kHz}$ \\
\hline
\end{tabular}

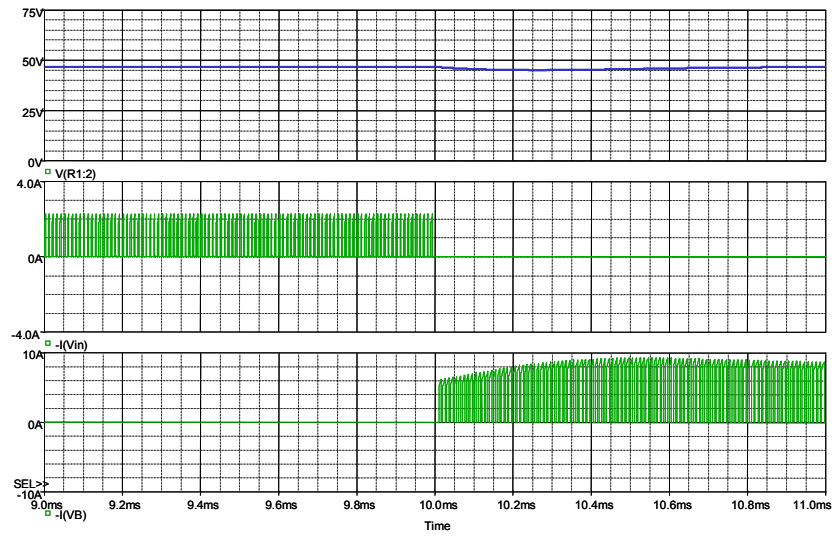

Figure 12. Output voltage (top trace), main current (center trace), and battery current (lower trace). The converter changes from the Normal to Back-up

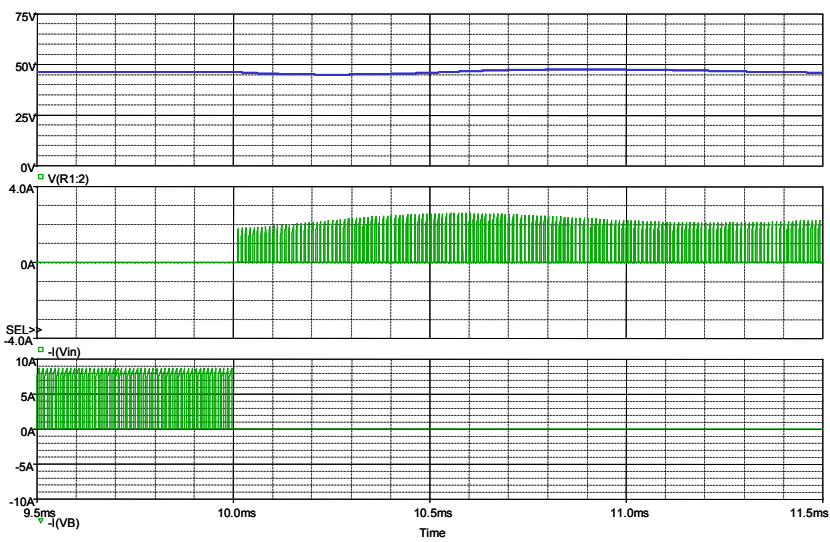

Figure 13. Output voltage (top trace), main current (center trace), and battery current (lower trace). The converter changes from Back-up to normal mode

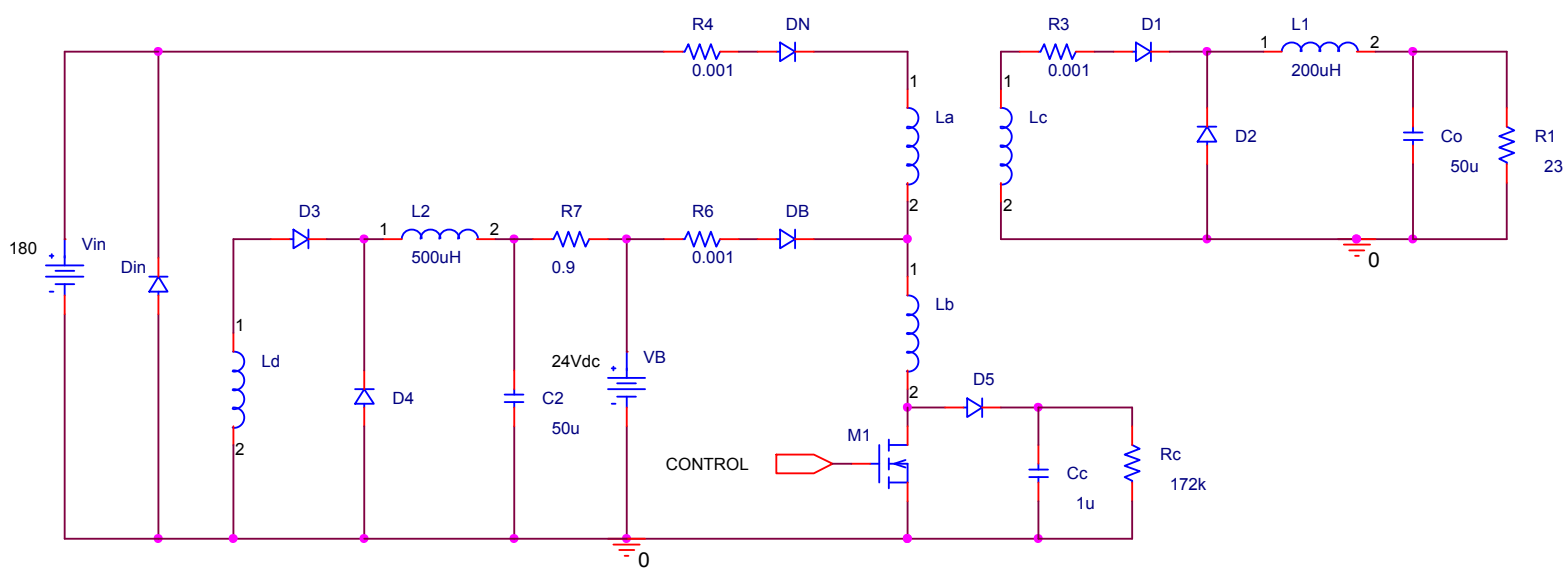

Figure 11. Schematic for simulate Forward-Forward DC-UPS with RCD network. 


\section{CONCLUSIONS}

A single simple structure of converters has been developed to make Automatic Transition without fail detects circuit. Preliminary results of the converter shows that is an interesting propose from point of view operation, size, dynamic response and cost because it is a very simple structure based in a Forward or Flyback converter with two outputs. Simulation and preliminary experimental results show that the converter shows a good operation. The answer of the circuit before failure of the main AC has been very fast and an output voltage has been obtained that as soon as it throughout varies the operation of the circuit. The transitions of operation in a one mode operation to another one do not suppose any change in the output voltage, as it were expected.

\section{REFERENCES}

[1] Karve, S., "Three of a kind [UPS topologies, IEC standard]" IEE Review, Volume: 46 Issue: 2 , March 2000

[2] Ma, K.-W.; Lee, Y.-S., "A novel uninterruptible DC-DC converter for UPS applications", Industry Applications Society Annual Meeting, 1991

[3] Kwok-Wai Ma; Yim-Shu Lee, "An integrated flyback converter for DC uninterruptible power supply", Applied Power Electronics Conference and Exposition (APEC), 1994

[4] Rodriguez, E.; Arau, J., "A novel DC-UPS with power factor correction in a single structure" Power Electronics Specialists Conference (PESC), 1996

[5] Jain, M.; Daniele, M.; Jain, P., "A high frequency triport topology for low power DC UPS”, Power Electronics Specialists Conference(PESC), 1998

[6] Rodriguez, E.; Abud, D.; Arau, J., "A novel single-stage single-phase DC uninterruptible power supply with power-factor correction", IEEE Transactions on Industrial Electronics, Volume: 46 Issue: 6, 1999

[7] Rodriguez, E.; Visairo, H.; Arau, J., "A high efficiency DC-UPS with PFC", Power Electronics Congress (CIEP), 2000

[8] Morrison, R.; Egan, M.G. "A new power-factor-corrected singletransformer UPS design", IEEE Transactions on Industry Applications, Volume: 36 Issue: 1 ,Jan.-Feb. 2000

[9] Fernandez, A.; Sebastian, J.; Martin-Ramos, J.A.; Corral, J.; Ruiz, F., "Multiple output AC/DC converter with an internal DC UPS", Power Electronics Specialists Conference (PESC), 2002

[10] Fuld, B., "A cost-effective DC/DC-converter with integrated UPSfunction", Power Electronics and Applications, Fifth European Conference on, 1993

[11] Yuan, X.M.; Lin, W.X., "Integrated uninterruptible DC converter with low input distortion and wide regulation capability", Power Electronics and Variable-Speed Drives, 1994

[12] Cheng, D.K.W.; Leung, F.H., "Design of a switching mode power supply with UPS features", Microelectronics and VLSI (TENCON), 1995

[13] García O., Alou P., Cobos J.A. and Uceda J., "Convertidor AC/DC con Back-up Integrado y Transición Automática", Seminario Anual de Automática, Electrónica Industrial e Instrumentación (SAAIE) 2003

[14] C.S. Leu, G.C. Hua, F.C. Lee, "Comparison of Forward Topologies with Various Reset Squemes", Virginia Power Electronics Center 